\title{
Triethylamine Enables Catalytic Generation of Oxidopyrylium Ylides for [5+2] Cycloadditions with Alkenes: An Efficient Entry to 8-Oxabicyclo[3.2.1]octane Frameworks
}

\author{
Yasunori Toda, ${ }^{\mathrm{a}}$ Masahiro Shimizu, ${ }^{\mathrm{a}}$ Taichi Iwai, ${ }^{\mathrm{a}}$ and Hiroyuki Suga ${ }^{\mathrm{a} *}$ \\ a Department of Materials Chemistry, Faculty of Engineering, Shinshu University, 4-17-1 Wakasato, Nagano 380-8553, \\ Japan \\ Fax: (+81)-26-269-5424; phone: (+81)-26-269-5392 \\ E-mail: sugahio@shinshu-u.ac.jp
}

Received: ((will be filled in by the editorial staff))

Supporting information for this article is available on the WWW under http://dx.doi.org/10.1002/adsc.201\#\#\#\#\#\#.((Please delete if not appropriate))

\begin{abstract}
An efficient method for the preparation of a range of 8-oxabicyclo[3.2.1] octane derivatives including synthetic intermediates of natural products is described, in which triethylamine effectively catalyzes [5+2] cycloaddition reactions between oxidopyrylium ylides and alkenes. This method can be applied not only to intermolecular cycloadditions with various alkenes but also to intramolecular cycloadditions. The key finding is that the combined use of organic bases having appropriate basicity and oxidopyrylium ylide precursors bearing a suitable leaving group facilitates the base-assisted generation of oxidopyrylium ylides in a catalytic manner.
\end{abstract}

Keywords: Cycloaddition; Organic Base; Base Catalysis; Oxidopyrylium Ylide; Alkenes

Organic bases are recognized as fundamental, conventional, and green catalysts and/or reagents in organic synthesis. Trialkylamines, such as triethylamine and diisopropylethylamine, are representative organobases, and have served as Brønsted or Lewis bases for numerous organic reactions. $^{[1]}$ Among these transformations, it is well known that hydroxypyranone derivatives undergo [5+2] cycloadditions with alkenes to construct an 8oxabicyclo[3.2.1]octane core, wherein an oxidopyrylium ylide intermediate $\mathbf{A}$ is generated with the help of a Brønsted base (Scheme 1a). ${ }^{[2-4]}$ Since [3.2.1] oxabicyclic ring systems are widely found in nature and biologically active compounds, e.g., englerins, polygalolides, descurainin, and cartorimine, ${ }^{[5]}$ these cycloadditions hold a prominent position in the synthesis of functionalized sevenmembered carbon skeletons (Figure 1). ${ }^{[6-8]}$ However, depending on the pattern of the substituents on the precursors, the yields of the cycloadducts can be low, and undesirable conditions (e.g., large excesses of bases and alkenes, high temperatures, or long reaction times) are often required.

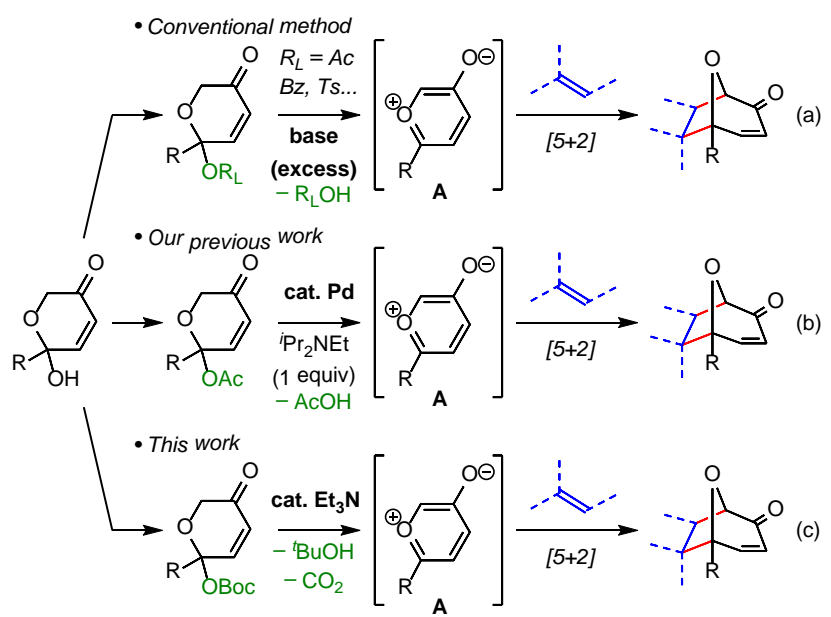

Scheme 1. Synthetic Access to 8-Oxabicyclo[3.2.1]octane Frame-works via Oxidopyrylium Ylides.
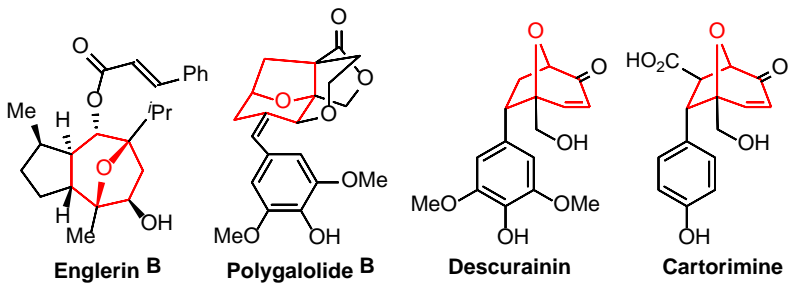

Figure 1. Natural products containing a [3.2.1] oxabicyclic ring.

We have recently reported the catalytic generation of oxidopyrylium ylide $\mathbf{A}$ from the corresponding acetoxypyranone using a palladium complex and an amine, which achieved efficient [5+2] cycloadditions with various alkenes (Scheme $1 \mathrm{~b}) .{ }^{\left[{ }^{[9]}\right.}$ We found it was important to maintain the appropriate concentration of $\mathbf{A}$ to suppress its decomposition and dimerization. 
This seems to be an inherent problem with the general method using acetoxypyranones as precursors, because a stochiometric amount of the amine is commonly employed in order to trap acetic acid derived from the leaving group. Therefore, if the catalytic use of amines is allowed, undesired side reactions would be avoided by controlling the rate of reactive intermediate formation. Thus, we reasoned that the introduction of a tert-butoxycarbonyl (Boc) group to the hydroxypyranone would enable the catalytic formation of $\mathbf{A}$ as follows (Scheme 1c): (i) tert-butylcarbonate turns into tert-butoxide along with the release of carbon dioxide, and (ii) this alkoxide deprotonates the ammonium ion to regenerate the free amine (Scheme 2) ${ }^{[10]}$ We report herein the triethylamine-catalyzed synthesis of 8oxabicyclo[3.2.1]octane entities from Boc-pyranones and alkenes under mild conditions, providing an alternative method to the employment of acetoxypyranones.

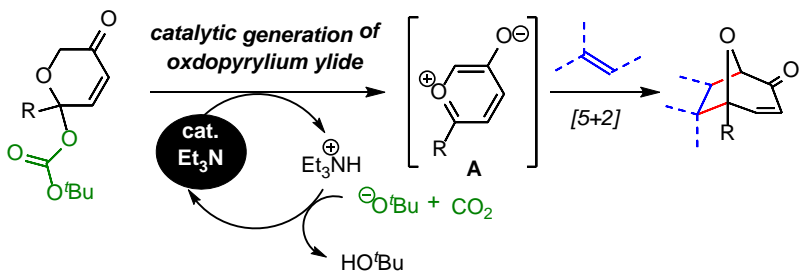

Scheme 2. Working Hypothesis.

The initial experiment was performed using Bocpyranone 1a, 5 equiv of styrene (2a), and $20 \mathrm{~mol} \%$ of triethylamine in a $0.13 \mathrm{M}$ solution of dichloromethane at $35{ }^{\circ} \mathrm{C}$. Even though a catalytic amount of triethylamine afforded cycloadduct 3a in good yield $(81 \%$, endo:exo $=80: 20)$ and only $6 \%$ of dimer $4^{[11]}$ was observed in the ${ }^{1} \mathrm{H}$ NMR spectrum of the unpurified reaction mixture, a long period of time (3 days) was needed for the consumption of starting material 1a (Table 1, entry 1). Switching the solvent to toluene, tetrahydrofuran, or acetonitrile led to disappointing results, although the reaction time was slightly shortened in the case of acetonitrile (Table 1, entries 2-4). The use of 1,2-dichloroethane as a solvent improved the yield of 3a up to $88 \%$. Finally, the reaction was completed within $24 \mathrm{~h}$ by raising the temperature $\left(50{ }^{\circ} \mathrm{C}\right)$ and increasing the concentration of the solution $(0.25 \mathrm{M})$, affording $3 \mathbf{a}$ in high yield $(89 \%$, endo:exo $=79: 21)$ (Table 1, entries 5-7). A comparison with other organic bases gave interesting results. 1,8-Diazabicyclo[5.4.0]undec-7-ene (DBU) has often been used for [5+2] cycloadditions in the reported procedure, but it was not effective in the present system (Table 1, entry 8). Moreover, 4dimethylaminopyridine (DMAP), diisopropylethylamine, and diethylamine, which have a relatively similar range of $\mathrm{pKa}$ values to their conjugate acids, resulted in low yields of 3a (Table 1, entries 9-11). ${ }^{[12,13]}$ These results imply that a proper
Brønsted basicity is crucial to achieving the catalytic cycle.

Table 1. Optimization of Reaction Conditions. ${ }^{[\mathrm{a}]}$

\begin{tabular}{|c|c|c|c|}
\hline$\underbrace{}_{\mathrm{OAC}}$ & 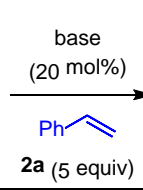 & exo $3 \mathbf{3 a c}$ & $\mathrm{DAc}_{4} \mathrm{OAC} /$ \\
\hline Entry & base & Conditions (M) & $\begin{array}{l}3 \mathbf{a}^{[\mathrm{b}]} \\
(\text { endo:exo })^{[\mathrm{c}]}\end{array}$ \\
\hline 1 & $\mathrm{Et}_{3} \mathrm{~N}$ & DCM (0.13), $35^{\circ} \mathrm{C}, 3 \mathrm{~d}$ & $81(80: 20)$ \\
\hline 2 & $\mathrm{Et}_{3} \mathrm{~N}$ & Tol (0.13), $35^{\circ} \mathrm{C}, 3 \mathrm{~d}$ & $57(79: 21)$ \\
\hline 3 & $\mathrm{Et}_{3} \mathrm{~N}$ & THF (0.13), $35^{\circ} \mathrm{C}, 3 \mathrm{~d}$ & $22(78: 22)$ \\
\hline 4 & $\mathrm{Et}_{3} \mathrm{~N}$ & $\operatorname{MeCN}(0.13), 35^{\circ} \mathrm{C}, 2 \mathrm{~d}$ & $70(78: 22)$ \\
\hline 5 & $\mathrm{Et}_{3} \mathrm{~N}$ & $\operatorname{DCE}(0.13), 35^{\circ} \mathrm{C}, 3 \mathrm{~d}$ & $88(79: 21)$ \\
\hline 6 & $\mathrm{Et}_{3} \mathrm{~N}$ & DCE (0.13), $50{ }^{\circ} \mathrm{C}, 2 \mathrm{~d}$ & $88(79: 21)$ \\
\hline 7 & $\mathrm{Et}_{3} \mathrm{~N}$ & DCE (0.25), $50{ }^{\circ} \mathrm{C}, 22 \mathrm{~h}$ & 89 (79:21) \\
\hline $8^{[\mathrm{d}]}$ & DBU & DCE (0.25), $50^{\circ} \mathrm{C}, 22 \mathrm{~h}$ & $31(80: 20)$ \\
\hline $9^{[\mathrm{d}]}$ & DMAP & DCE (0.25), $50^{\circ} \mathrm{C}, 22 \mathrm{~h}$ & $33(79: 21)$ \\
\hline $10^{\text {[d] }}$ & ${ }^{i} \mathrm{Pr}_{2} \mathrm{NEt}$ & DCE (0.25), $50^{\circ} \mathrm{C}, 22 \mathrm{~h}$ & $35(78: 22)$ \\
\hline $11^{[\mathrm{d}]}$ & $\mathrm{Et}_{2} \mathrm{NH}$ & DCE (0.25), $50^{\circ} \mathrm{C}, 22 \mathrm{~h}$ & 0 \\
\hline
\end{tabular}

[a] All reactions were carried out on a $0.25 \mathrm{mmol}$ scale using $\mathbf{1 a}$ and 5 equiv of styrene (2a). ${ }^{[b]}$ Isolated yield. ${ }^{[c]}$ Determined by ${ }^{1} \mathrm{H}$ NMR analysis. ${ }^{[\mathrm{d}]}$ Recovery of 1a: entry 8, 30\%; entry 9, $12 \%$; entry $10,64 \%$; entry $11,70 \%$. The values of $\mathrm{pK}_{\mathrm{BH}}+$ in $\mathrm{CH}_{3} \mathrm{CN}$ : DBU, 24.34; $\mathrm{Et}_{3} \mathrm{~N}, 18.82$; DMAP, 17.95, see ref 12a.

The scope of substrates is summarized in Scheme 3. First, a series of alkenes $\mathbf{2}$ was examined to probe the generality of the catalytic system using 1a. Electronrich styrene $\mathbf{2 b}$ selectively afforded endo-3b (94\%, endo:exo $=92: 8$ ), which is a precursor of descurainin. Vinyl ethers 2c-2e were also found to give only endo-adducts $\mathbf{3} \mathbf{c}-\mathbf{3 e}$ in good yields. In the case of acrylate $\mathbf{2 f}$, the reaction proceeded smoothly, affording $\mathbf{3 f}$ and its regioisomer. Electron-deficient internal alkenes such as dimethyl fumarate (2g) and $\mathrm{N}$-phenyl maleimide (2h) were also tolerated albeit with low diastereoselectivities of $\mathbf{3 g}$ and $\mathbf{3 h}$. Notably, the use of exocyclic methylenes $\mathbf{2} \mathbf{i}-\mathbf{2 l}$ resulted in mostly good to high yields of cycloadducts $3 \mathbf{i}-\mathbf{3} \mathbf{l}$, probably due to their relatively high reactivities. ${ }^{[14]}$ Next, oxidopyrylium ylide precursors $\mathbf{1 b}$ and $\mathbf{1 c}$ were tested in the cycloaddition with $2 \mathbf{2 a}$. The reaction using $\mathbf{1 b}$ bearing a siloxymethyl group was sluggish and required over 2 days at $50{ }^{\circ} \mathrm{C}$ to complete, but product $3 \mathrm{~m}$ was obtained in good yield $(78 \%$, endo:exo = 72:28). An attempt to increase the temperature to $100{ }^{\circ} \mathrm{C}$ in a sealed tube resulted in rapid conversion of $\mathbf{1 b}$ for $6 \mathrm{~h}$, but a similar yield $(72 \%$, endo:exo $=70: 30)$ was obtained. On the other hand, no significant difference between 1c and 1a was observed in terms of the reactivity toward $\mathbf{2 a}$. Vinyl ether 2d also underwent the cycloaddition with 1c-derived oxidopyrylium ylide, providing endo-3o with perfect stereoselectivity as in the reaction using 1a. In contrast, the use acrylate $2 \mathbf{f}$ led to the formation of a 1:1 endo/exo mixture of $\mathbf{3 p}$ and their 
regioisomers. In the cases of alkenes $\mathbf{2} \mathbf{g}-\mathbf{2 l}$, the yields of $\mathbf{3 q}-\mathbf{3 u}$ were good to high, whereas the diastereoselectivities were modest.
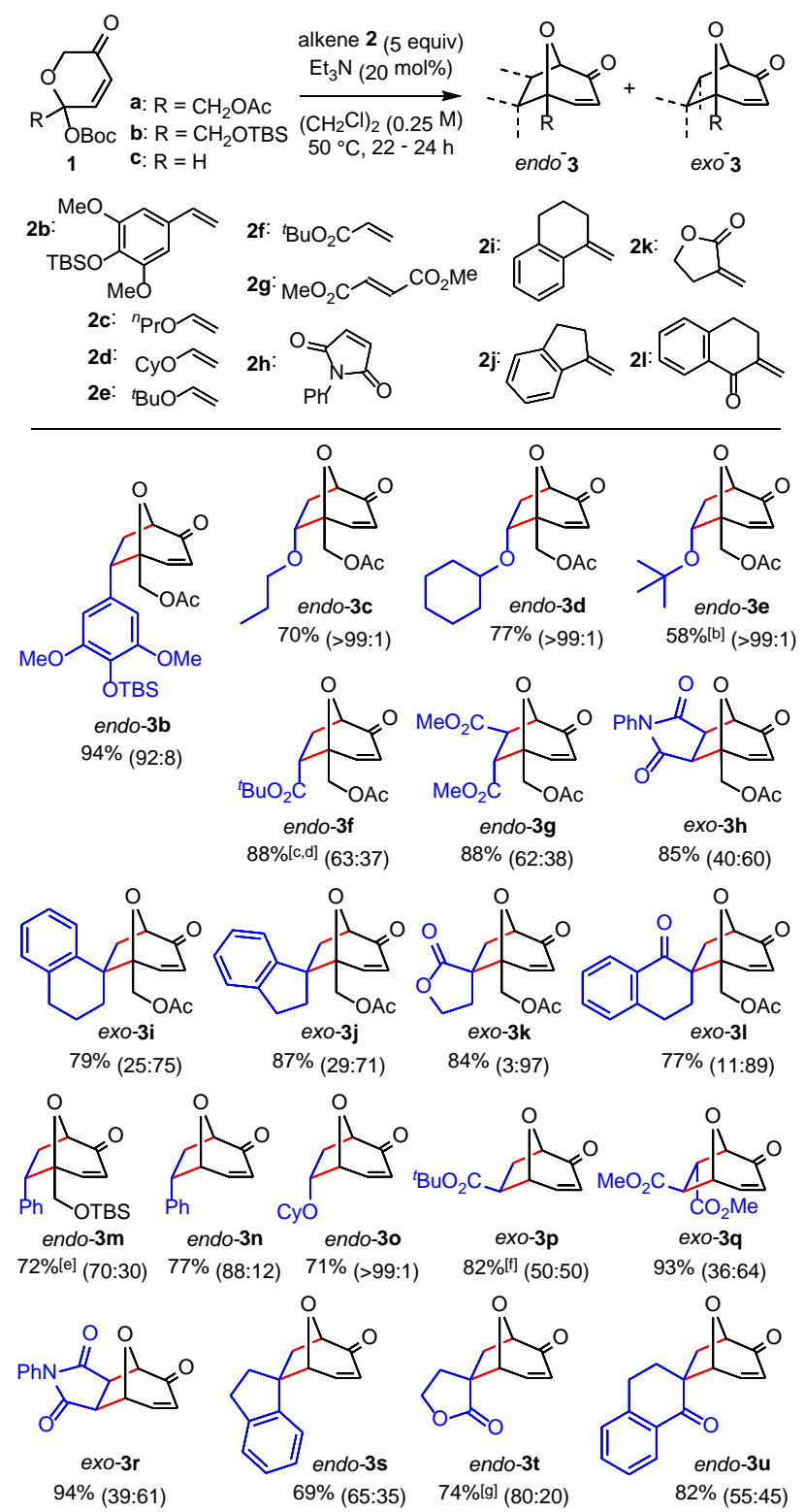

[a] Unless otherwise noted, all reactions were carried out on a 0.25 mmol scale using 1a and 5 equiv of alkene 2 in 1,2dichloroethane $(0.25 \mathrm{M})$ at $50^{\circ} \mathrm{C}$. The diastereoselectivities were determined by ${ }^{1} \mathrm{H}$ NMR analysis and are shown in parentheses (endo:exo). The structure of major diastereomers obtained is shown. [b] 28 h. ${ }^{\text {[c] }} 30$ h. ${ }^{\text {[d] }} 13 \%$ of regioisomer was included. [e] $100{ }^{\circ} \mathrm{C}, 6 \mathrm{~h}$. [f] $5 \%$ of regioisomer was included. [g] $9 \%$ of regioisomer was included.

Scheme 3. Substrate Scope. ${ }^{[a]}$

Further scope of $\mathbf{1}$ was examined as shown in Scheme 4. 2-Methyl-substituted Boc-pyranone 1d was challenging, and less than $50 \%$ of the corresponding adduct $3 \mathbf{v}$ was formed at $50{ }^{\circ} \mathrm{C}(54 \%$ conversion of 1d). To our delight, a higher temperature facilitated the reaction, leading to a better yield of $3 \mathbf{v}$ (Scheme 4a). To expand the applicability of our methodology, intramolecular [5+2] cycloadditions using $\mathbf{1 e}$ and $\mathbf{1 f}$ were tested. ${ }^{[15]}$ At $100{ }^{\circ} \mathrm{C}$ for $6 \mathrm{~h}$, oxidopyrylium ylides generated from 1e and 1f reacted with internal alkenes to afford tricyclic cycloadducts $\mathbf{3 w}$ and $\mathbf{3 x}$ in good yields with perfect exo-selectivities in both cases (Scheme 4b). ${ }^{[16]}$

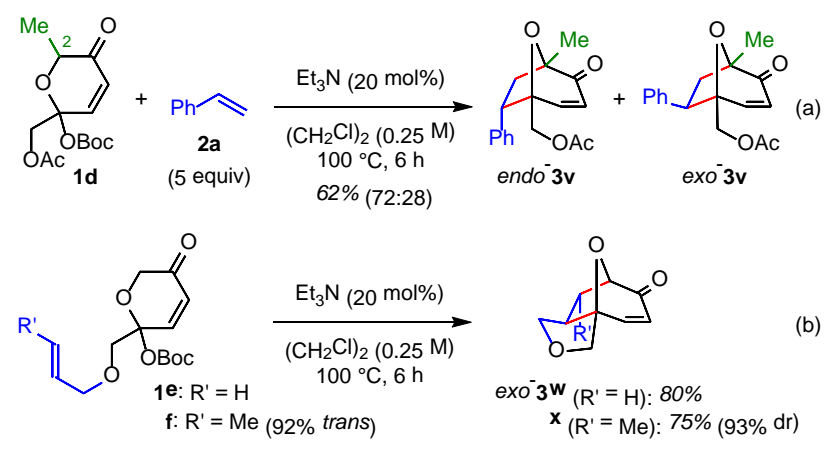

Scheme 4. Further Exploration of Reaction Scope.

In order to evaluate the triethylamine catalysis, we conducted control experiments by changing the amount of triethylamine. It is of interest that the yield of 3a tended to decrease in the presence of more than a stoichiometric amount of triethylamine (Figure 2a). ${ }^{[17]}$ In addition, the excess base induced formation of 4, which clearly reveals that catalytic oxidopyrylium ylide generation has the advantage of preventing this undesired process. The same experiments were conducted for Ac-pyranone 5, which bears a typical leaving group $\left(\mathrm{OR}_{\mathrm{L}}\right)$, in the [5+2] cycloadditions. Notably, $100 \mathrm{~mol} \%$ of triethylamine gave the highest yield and the productivity of 3a dropped not only under $200 \mathrm{~mol} \%$ but also under $20 \mathrm{~mol} \%$ conditions (Figure $2 \mathrm{~b}$ ). These results suggest that excess base is not necessarily good for this type of transformation, which might have caused the low yields of cycloadducts in the previous reports. ${ }^{[7 b, c]}$ Most importantly, introduction of a Boc group enabled the organic base to convert substrates to products in catalytic fashion.

In summary, we have demonstrated efficient triethylamine-catalyzed [5+2] cycloaddition between oxidopyrylium ylides and alkenes. A series of dipolarophiles were tolerated to afford the cycloadducts in good to high yields. This method is also applicable to intramolecular [5+2] cycloadditions to provide fused seven-membered rings with an oxygen bridge. Further applications of organobasecatalyzed oxidopyrylium ylide cycloadditions in the synthesis of complex molecules are currently underway in our laboratory. 


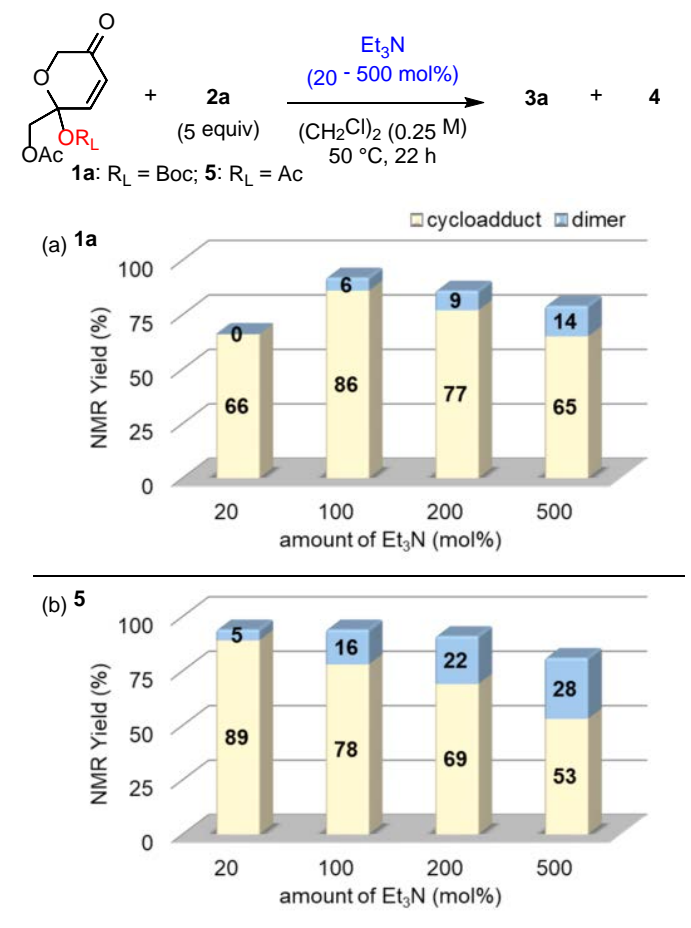

Figure 2. Correlation between amount of triethylamine and yield of cycloadduct 3a. (a) Results of reactions using 1a. (b) Results of reactions using 5.

\section{Experimental Section}

\section{General Procedure for the Triethylamine-Catalyzed} Intermolecular Cycloaddition.

To a Schlenk tube equipped with a stir bar was added 1a (71.6 mg, 0.25 mmol, 1.0 equiv), $\left(\mathrm{CH}_{2} \mathrm{Cl}\right)_{2}(1.0 \mathrm{~mL}), 2 \mathrm{a}$ (144 $\mu \mathrm{L}, 1.25$ mmol, 5.0 equiv), and $\mathrm{Et}_{3} \mathrm{~N}$ (7.0 $\mu \mathrm{L}, 0.05$ mmol, $20 \mathrm{~mol} \%$ ). The mixture was stirred at $50^{\circ} \mathrm{C}$ for $22 \mathrm{~h}$, and then concentrated. Silica gel column chromatography (10 g, Hexane/EtOAc = 4/1) yielded 3a (60.5 mg, 89\%, endo:exo $=79: 21)$ as colorless oil.

\section{General Procedure for the Triethylamine-Catalyzed} Intramolecular Cycloaddition.

To a sealed tube equipped with a stir bar was added 1e (71.1 mg, $0.25 \mathrm{mmol}, 1.0$ equiv), $\left(\mathrm{CH}_{2} \mathrm{Cl}\right)_{2}(1.0 \mathrm{~mL})$, and $\mathrm{Et}_{3} \mathrm{~N}(7.0 \mu \mathrm{L}, 0.05 \mathrm{mmol}, 20 \mathrm{~mol} \%)$. The mixture was stirred at $100{ }^{\circ} \mathrm{C}$ for $6 \mathrm{~h}$, and then concentrated. Silica gel column chromatography (8 g, Hexane/EtOAc = 2/1) yielded 3w (33.1 mg, 80\%, exo) as colorless plates.

\section{Acknowledgements}

This work was partially supported by the Japan Society for the Promotion of Science (JSPS) through a Grant-in-Aid for Scientific Research (C) (Grant No. JP15K05497).

\section{References}

[1] a) K. Eller, E. Henkes, R. Rossbacher, H. Höke, Amines, Aliphatic. Ullmann's Encyclopedia of Industrial Chemistry, 2000; b) K. L. Sorgi, Triethylamine. e-EROS Encyclopedia of Reagents for Organic Synthesis, 2001; c) K. L. Sorgi,
Diisopropylethylamine. e-EROS Encyclopedia of Reagents for Organic Synthesis, 2001. For organocatalysis: d) C. Palomo, M. Oiarbide, R. López, Chem. Soc. Rev. 2009, 38, 632-653. e) A. Ting, J. M. Goss, N. T. McDougal, S. E. Schaus, Top. Curr. Chem. 2010, 291, 145-200; f) A. Ting, S. E. Schaus in Comprehensive Enantioselective Organocatalysis: Catalysts, Reactions, and Applications, Vol. 2 (Ed.: P. I. Dalko), Wiley-VCH, Weinheim, 2013, pp. 343-363.

[2] For pioneer studies, see: a) K. T. Potts, A. J. Elliott, M. Sorm, J. Org. Chem. 1972, 37, 3838-3845; b) J. B. Hendrickson, J. S. Farina, J. Org. Chem. 1980, 45, 3359-3361; c) J. B. Hendrickson, J. S. Farina, J. Org. Chem. 1980, 45, 3361-3363; d) P. G. Sammes, L. J. Street, J. Chem. Soc., Perkin Trans. 1 1983, 12611265; e) P. G. Sammes, L. J. Street, P. Kirby, J. Chem. Soc., Perkin Trans. 1 1983, 2729-2734; f) P. G. Sammes, L. J. Street, J. Chem. Res. (S) 1984, 196-197; g) N. Ohmori, T. Miyazaki, S. Kojima, K. Ohkata, Chem. Lett. 2001, 30, 906-907.

[3] For acid-mediated generation, see: P. Magnus, L. Shen, Tetrahedron 1999, 55, 3553-3560.

[4] For asymmetric variants, see: a) N. Z. Burns, M. R. Witten, E. N. Jacobsen, J. Am. Chem. Soc. 2011, 133, 14578-14581; b) M. R.Witten, E. N. Jacobsen, Angew. Chem. 2014, 126, 6022-6026; Angew. Chem. Int. Ed. 2014, 53, 5912-5916; c) A. Orue, U. Uria, E. Reyes, L. Carrillo, J. L. Vicario, Angew. Chem. 2015, 127, 30863089; Angew. Chem. Int. Ed. 2015, 54, 3043-3046. d) D. Roca-López, U. Uria, E. Reyes, L. Carrillo, K. A. Jørgensen, J. L. Vicario, P. Merino, Chem. Eur. J. 2016, 22, 884-889; e) K. N. Fuhr, D. R. Hirsch, P. Murelli, S. E. Brenner-Moyer, Org. Lett. 2017, 19, 6356-6359.

[5] Englerins: a) R. Ratnayake, D. Covell, T. T. Ransom, K. R. Gustafson, J. A. Beutler, Org. Lett. 2009, 11, 57-60; intricarene: b) J. Marrero, A. D. Rodríguez, C. L. Barnes, Org. Lett. 2005, 7, 1877-1880; anthecularin: c) A. Karioti, H. Skaltsa, A. Linden, R. Perozzo, R. Brun, D. Tasdemir, J. Org. Chem. 2007, 72, 8103-8106; polygalolides: d) W. Ma, X. Wei, T. Ling, H. Xie, W. Zhou, J. Nat. Prod. 2003, 66, 441-443; descurainin: e) K. Sun, X. Li, W. Li, J. Wang, J. Liu, Y. Sha, Chem. Pharm. Bull. 2004, 52, 1483-1486; cartorimine: f) H.B. Yin, Z.-S. He, Y. Ye, J. Nat. Prod. 2000, 63, 1164 1165.

[6] For reviews, see: a) V. Singh, U. M. Krishna, Vikrant, G. K. Trivedi, Tetrahedron 2008, 64, 3405-3428; b) H. Pellissier, Adv. Synth. Catal. 2011, 353, 189-218; c) K. E. O. Ylijoki, J. M. Stryker, Chem. Rev. 2013, 113, 2244-2266. See also: d) M. A. Battiste, P. M. Pelphrey, D. L. Wright, Chem. Eur. J. 2006, 12, 3438-3447; e) T. V. Nguyen, J. M. Hartmann, D. Enders, Synthesis 2013, $45,845-873$

[7] Englerins: a) K. C. Nicolaou, Q. Kang, S. Y. Ng, D. Y.K. Chen, J. Am. Chem. Soc. 2010, 132, 8219-8222; polygalolides: b) B. B. Snider, X. Wu, S. Nakamura, S. Hashimoto, Org. Lett. 2007, 9, 873-874; descurainin and cartorimine: c) B. B. Snider, J. F. Grabowski, Tetrahedron 2006, 62, 5171-5177; intricarene: d) P. A. 
Roethle, P. T. Hernandez, D. Trauner, Org. Lett. 2006, 8, 5901-5904; e) B. Tang, C. D. Bray, G. Pattenden, Tetrahedron Lett. 2006, 47, 6401-6404; f) B. Tang, C. D. Bray, G. Pattenden, Org. Biomol. Chem. 2009, 7, 4448-4457; anthecularin: g) Y. Li, C. C. Nawrat, G. Pattenden, J. M. Winne, Org. Biomol. Chem. 2009, 7, 639-640; hainanolidol and harringtonolide: h) $M$. Zhang, N. Liu, W. Tang, J. Am. Chem. Soc. 2013, 135, 12434-12438; santalin Y: i) S. Strych, G. Journot, R. P. Pemberton, S. C. Wang, D. J. Tantillo, D. Trauner, Angew. Chem. 2015, 127, 5168-5172; Angew. Chem. Int. Ed. 2015, 54, 5079-5083; colchicine, demecolcinone, and metacolchicine: (j) B. Chen, X. Liu, Y.-J. Hu, D.-M. Zhang, L. Deng, J. Lu, L. Min, W.-C. Ye, C.-C. Li, Chem. Sci. 2017, 8, 4961-4966.

[8] The [3.2.1]oxabicyclic ring system has also been shown to be a versatile intermediate for transformation to functionalized seven-membered carbon skeletons. $\beta$ Bulnesene: a) S. M. Bromidge, P. G. Sammes, L. J. Street, J. Chem. Soc., Perkin Trans. 1 1985, 17251730; phorbol: b) P. A. Wender, H. Kogen, H. Y. Lee, J. D. Munger, Jr., R. S. Wilhelm, P. D. Williams, J. Am. Chem. Soc. 1989, 111, 8957-8958; c) P. A. Wender, K. D. Rice, M. E. Schnute, J. Am. Chem. Soc. 1997, 119, 7897-7898; resiniferatoxin: d) P. A. Wender, C. D. Jesudason, H. Nakahira, N. Tamura, A. L. Tebbe, Y. Ueno, J. Am. Chem. Soc. 1997, 119, 12976-12977; bicyclo[5.4.0] undecane: e) D. R. Williams, J. W. Benbow, J. G. McNutt, E. E. Allen, J. Org. Chem. 1995, 60, 833-843; deoxy epolone B: f) R. M. Adlington, J. E. Baldwin, A. V. W. Mayweg, G. J. Pritchard, Org. Lett. 2002, 4, 3009-3011; pseudolaric acid A: g) Z. Geng, B. Chen, P. Chiu, Angew. Chem. 2006, 118, 6343-6347; Angew. Chem. Int. Ed. 2006, 45, 6197-6201; sundiversifolide: h) M. Kawasumi, N. Kanoh, Y. Iwabuchi, Org. Lett. 2011, 13, 3620-3623; dolastatrienol: i) L. T. Leung, P. Chiu, Chem. Asian J. 2015, 10, 1042-1049.

[9] H. Suga, T. Iwai, M. Shimizu, K. Takahashi, Y. Toda, Chem. Commun. 2018, 54, 1109-1112.
[10] a) O'Doherty and co-workers reported palladiumcatalyzed glycosylation reactions using Boc-pyranones. R. S. Babu, G. A. O'Doherty, J. Am. Chem. Soc. 2003, 125, 12406-12407; b) $\mathrm{Li}$ and co-workers reported stoichiometric base-promoted intramolecular [5+2] cycloadditions of oxidopyrylium ylides. X. Liu, J. Liu, J. Zhao, S. Li, C.-C. Li, Org. Lett. 2017, 19, 2742-2745.

[11] Dimer 4 can be isolated by silica gel column chromatography. The reaction of $\mathbf{4}$ with $2 \mathbf{2}$ under heating conditions did not give cycloadduct $\mathbf{3 a}$.

[12] a) I. Kaljurand, A. Kütt, L. Sooväli, T. Rodima, V. Mäemets, I. Leito, I. A. Koppel, J. Org. Chem. 2005, 70, 1019-1028; b) E. L. Woodall, J. A. Simanis, C. G. Hamaker, J. R. Goodell, T. A. Mitchell, Org. Lett. 2013, 15, 3270-3273.

[13] The results of the reaction using other tertiary amines are shown in the supporting information.

[14] Cycloadduct 3k can be converted to polygalolides A and B. S. Nakamura, Y. Sugano, F. Kikuchi, S. Hashimoto, Angew. Chem. 2006, 118, 6682-6685; Angew. Chem. Int. Ed. 2006, 45, 6532-6535. See also: ref $7 \mathrm{~b}$ and 9 .

[15] a) A. Rumbo, L. Castedo, A. Mourino, J. L. Mascareñas, J. Org. Chem. 1993, 58, 5585-5586; b) J. L. Mascareñas, I. Pérez, A. Rumbo, L. Castedo, Synlett 1997, 81-82; c) S. Celanire, F. Marlin, J. E. Baldwin, R. M. Adlington, Tetrahedron 2005, 61, 3025-3032.

[16] The diastereoselectivity of $\mathbf{3 x}$ corresponds to trans/cis-isomers of alkene 1f (major: exo-3x bearing an endo-methyl group, minor: exo-3x bearing an exomethyl group).

[17] Control experiments for the reaction of $\mathbf{1 a}$ with $\mathbf{2 d}$, $\mathbf{2 h}$, and $\mathbf{2 k}$ were conducted under $200 \mathrm{~mol} \%$ conditions. In addition, the reaction using 1f under 200 mol\% conditions was carried out, see supporting information for details. 


\section{COMMUNICATION}

Triethylamine Enables Catalytic Generation of Oxidopyrylium Ylides for [5+2] Cycloadditions with Alkenes: An Efficient Entry to 8-

Oxabicyclo[3.2.1] octane Frameworks

Adv. Synth. Catal. Year, Volume, Page - Page

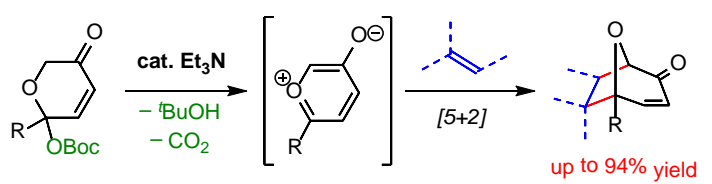

Yasunori Toda, Masahiro Shimizu, Taichi Iwai, and Hiroyuki Suga* 